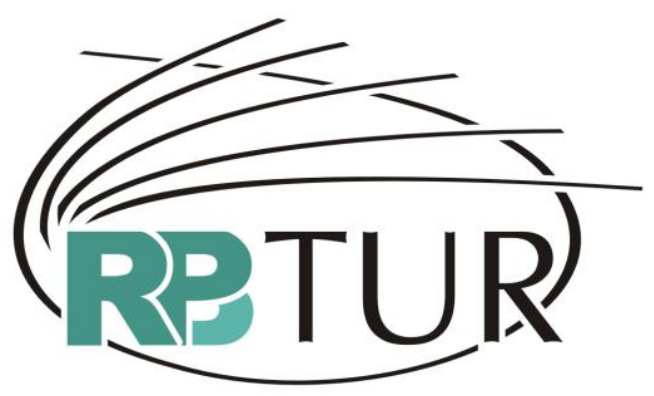

REVISTA BRASILEIRA DE PESQUISA EM TURISMO

\title{
PRÁTICAS DE ETNOCONHECIMENTO NA GESTÃO PARTICIPATIVA DO TURISMO SUSTENTÁVEL NA AMAZÔNIA: QUILOMBO DE TAPANAGEM (ORIXIMINÁ, PA, BRASIL)
}

\author{
ETHNO-KNOWLEDGE PRACTICES IN PARTICIPATORY \\ MANAGEMENT FOR SUSTAINABLE TOURISM AT AMAZONIA: \\ TAPANAGEM QUILOMBO (ORIXIMINA/PARÁ STATE, BRAZIL)
}

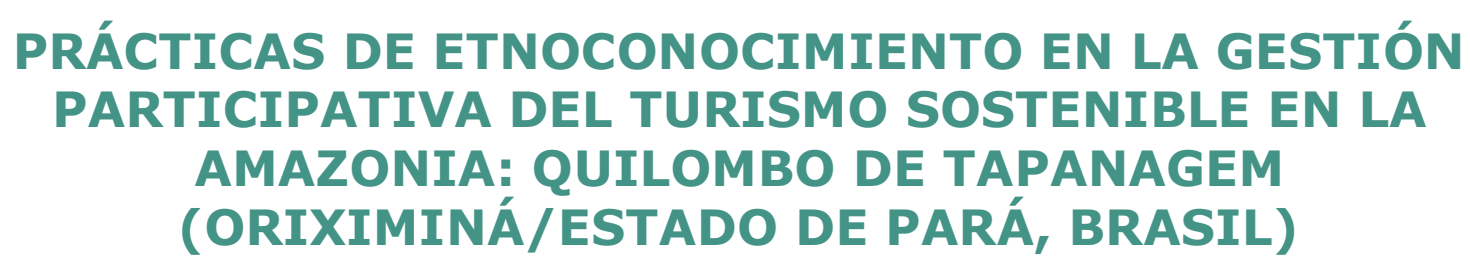

Leonardo Gama Campos ${ }^{1}$ Cristiane Passos de Mattos $^{2}$

\begin{abstract}
Resumo: Este trabalho busca analisar a utilização de práticas de etnomapeamento como auxílio à gestão participativa sustentável do turismo em áreas habitadas por populações tradicionais que possuem seus territórios em áreas próximas, justapostas ou sobrepostas a diferentes áreas protegidas na Amazônia. Com foco em uma microrregião do Alto Rio Trombetas (Oriximiná, PA, Brasil), estuda o Quilombo Tapagem a partir de trabalhos de campo, pesquisa bibliográfica, análise documental, observação participante e técnicas de diagnóstico rural participativo (DRP). Discorre sobre as abordagens e mapas participativos no âmbito da gestão da biodiversidade, e apresenta os resultados da pesquisa. A análise dos diferentes usos dos recursos naturais do território estudado por meio do mapeamento participativo na micro-região estudada se coloca enquanto uma ferramenta útil à formulação de políticas públicas para o desenvolvimento do turismo sustentável.
\end{abstract}

Palavras chave: Turismo sustentável. Populações tradicionais. Metodologia participativa. Etnomapeamento. Oriximiná (PA, Brasil).

${ }^{1}$ Licenciado e Bacharel em Geografia - Universidade Federal Fluminense (UFF), Especialista em Ensino de Geografia - Universidade do Estado do Rio de Janeiro (UERJ), Mestre em Ciência Ambiental (UFF) e Doutorando em Geografia (UFF). Email: leogeouff@yahoo.com.br

${ }^{2}$ Licenciada e Mestre em Geografia (UFF). Professora do Curso Superior de Tecnologia em Gestão do Turismo do Centro Federal de Educação Tecnológica Celso Suckow da Fonseca CEFET/RJ Nova Friburgo. Email: cristianepassos@yahoo.com.br 
Abstract: The article analyses the use of ethno-mapping practices to help participatory management of sustainable tourism in areas tha are inhabited by traditional populations near or within protected areas at Amazonia. Focusing in the Alto Trombetas River microarea, at Oriximina, Para State, Brasil, Quilombo Tapagem is studied through field work, bibliographical and documental analysis as well as participatory observation and participatory rural diagnosis techniques. Approaches and participatory maps on the issue of biodiversity are described as well as research results. Analysis of the different uses assigned for natural resources through participatory mapping appears to be a usefull tool for public policies intiatives for sustainable tourism development.

Keywords: Sustainable tourism. Traditional populations. Participatory methodology. Etnomapping. Oriximiná (Pará State, Brazil).

Resumen: Este trabajo busca analizar la utilización de prácticas de etnomapeamento como auxilio a la gestión participativa sustentable del turismo en áreas habitadas por poblaciones tradicionales que tienen sus territorios en áreas próximas, o superpuestas a diferentes áreas protegidas en la Amazonia. Focalizando en una microrregión del Alto Rio Trombetas (Oriximiná/PA, Brasil), estudia el Quilombo Tapagem a partir de trabajos de campo, investigación bibliográfica, análisis documental, observación participante y técnicas de diagnóstico rural participativo (DRP). Describe las aproximaciones y los mapas participativos dentro de la gestión de la biodiversidad, y presenta los resultados. El análisis de los diferentes usos de los recursos naturales del territorio estudiado por medio del mapeamiento participativo se presenta como una herramienta útil para la formulación de políticas públicas para el desarrollo del turismo sostenible.

Palabras clave: Turismo sostenible. Poblaciones tradicionales. Metodología participativa. Etnomapeamiento. Oriximiná (Estado de Pará, Brasil).

\section{Introdução}

A Amazônia brasileira constitui imenso patrimônio de terras, de recursos naturais e culturas específicas. Além de sua reconhecida riqueza natural, abriga expressivo conjunto de povos indígenas e populações tradicionais, que incluem seringueiros, castanheiros, ribeirinhos, babaçueiras, quilombolas, entre outros, o que Ihe confere destaque em termos de diversidade cultural (BRASIL, 2002).

Esta diversidade de recursos e culturas amazônicos é vista, muitas vezes, como inesgotável, uma vez que a base de crescimento econômico no Brasil tem sido o patrimônio natural, fundamentando-se na incorporação contínua de terras e recursos naturais percebidos como inesgotáveis, dentro da lógica capitalista de acumulação e desenvolvimento (BOULDING, 1966 apud Becker, 
2005). Mas, atualmente, a partir da emergência do paradigma da sustentabilidade, diversos setores da sociedade buscam compatibilizar ações de desenvolvimento econômico e conservação ambiental.

No município de Oriximiná (Pará), região do Alto Rio Trombetas, encontra-se uma significativa gama de atores sociais: caboclos ribeirinhos, índios, comunidades urbanas e diversas comunidades remanescentes de quilombos, constituídas por descendentes de escravos fugidos no final do século XVII (ACEVEDO; CASTRO, 1998).

A região, coberta predominantemente pela floresta ombrófila densa, é considerada uma área prioritária para a conservação, possuindo duas unidades de conservação (UC's) com aproximadamente 800 mil hectares: a Reserva Biológica (REBIO) do Rio Trombetas e a Floresta Nacional (FLONA) SaracáTaquera, administradas atualmente pelo Instituto Chico Mendes de Conservação da Biodiversidade (ICMBio). Concomitantemente a isso, observase a atuação de uma grande multinacional do ramo de mineração com a extração da bauxita no interior da FLONA Saracá-Taquera: a Mineração Rio do Norte S.A. (MRN).

Como subsídio a possíveis planos de desenvolvimento turístico sustentável articulados aos conhecimentos autóctones, observando-se a legitimidade das diferentes matrizes culturas de conhecimento, apresenta-se o etnoconhecimento quilombola materializado por meio do mapeamento participativo e do mapa êmico como um instrumento capaz de aproximar distintos conhecimentos em prol de uma gestão participativa de atividades turísticas sustentáveis. Nesse contexto, busca-se neste artigo discutir a relevância da inserção das populações tradicionais na elaboração de estratégias e ações conservacionistas para projetos de desenvolvimento turístico através de métodos participativos que estimulem a produção e a sistematização desses conhecimentos.

Segundo Diegues (2000), essas populações apresentam características em comum, utilizando-se de técnicas de manejo de recursos naturais de baixo impacto, modos eqüitativos de organização social, com a presença de 
instituições com legitimidade para fazer cumprir suas leis, liderança local e traços locais culturais peculiares que são seletivamente reafirmados e reelaborados. Além disso, esses grupos têm em comum o fato de possuírem interesses em manter ou recuperar o controle sobre o território vivenciado. Mas, acima de tudo, estão dispostos a uma negociação: em troca do controle sobre o território, comprometem-se a prestar serviços ambientais.

Este trabalho se caracteriza como um estudo de caso de caráter exploratório na comunidade remanescente de quilombo Tapagem, localizada na micro-região do Alto Rio Trombetas, município de Oriximiná, Estado do Pará (Figura 1), durante o período de 09/02/2008 a 24/02/2008. Baseia-se em trabalhos de campo, pesquisa bibliográfica e análise documental, além de observação participante e técnicas de diagnóstico rural participativo (DRP). Parte de fundamentos teóricos sobre a gestão da biodiversidade, tratando de abordagens e mapas participativos, para em seguida abordar os remanescentes e o mapeamento participativo no Quilombo da Tapagem. 


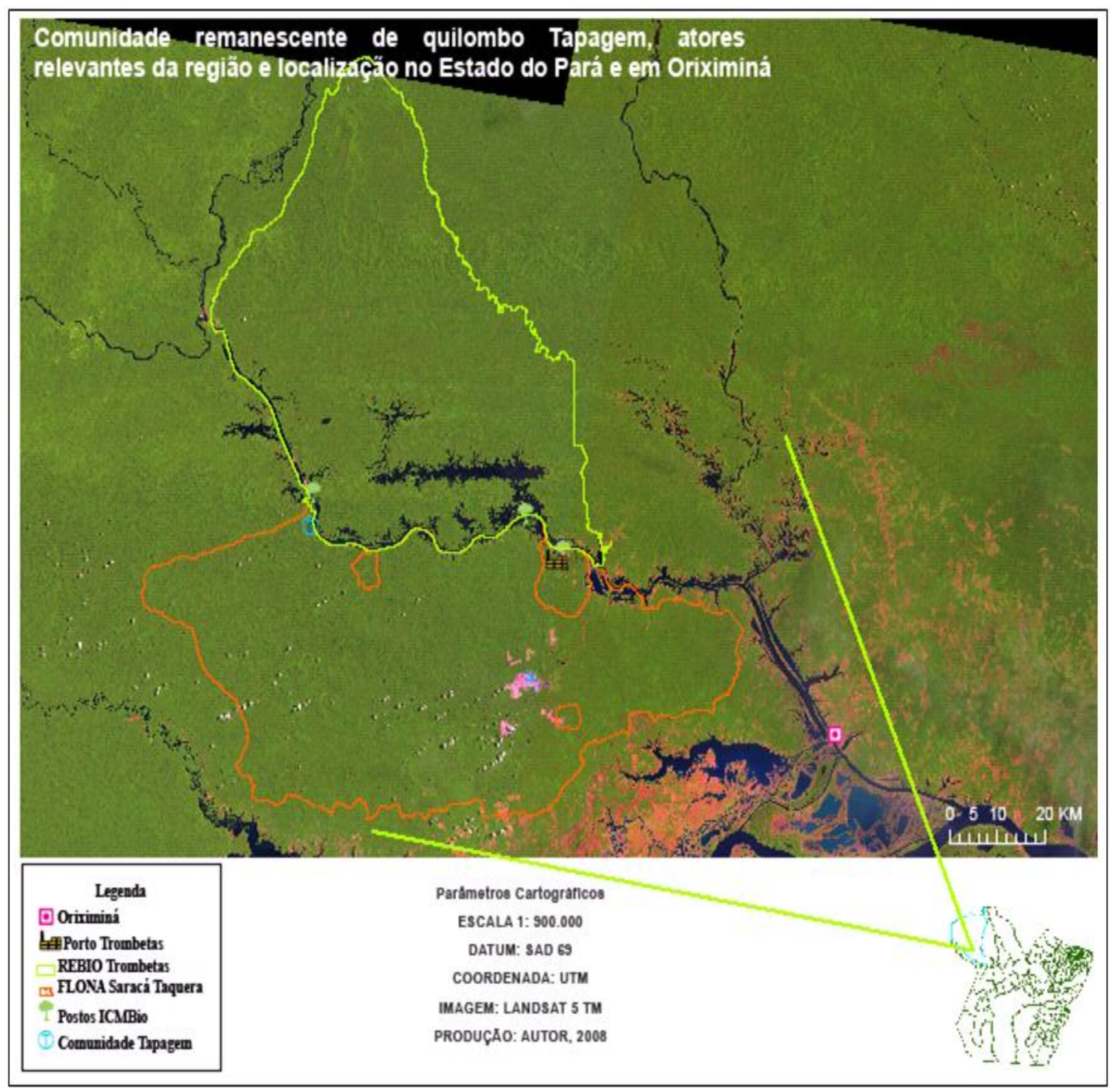

Figura 1 - Micro-região do Alto Rio Trombetas, Oriximiná (PA)

\section{Gestão da Biodiversidade: Abordagens e Mapas Participativos}

A participação da sociedade nos processos de decisão envolvendo o meio ambiente e seus interesses tem sido uma constante nos últimos anos. Pimbert e Pretty (2000) enfatizam o reconhecimento do papel do envolvimento comunitário nos processos de conservação no âmbito da gestão da biodiversidade argumentando que quando as comunidades não são envolvidas os custos operacionais de manejo e conservação são muito onerosos. Theodoro (2005) entende a participação como mais do que uma ação mecânica de escolha de representante, mas uma tentativa de partilhar um lugar no mapa, 
criando uma identidade coletiva que envolva a crença de que, quando as pessoas se abrem umas com as outras se forma um tecido que as mantém unidas.

No Brasil, particularmente na Amazônia, muitas áreas destinadas à conservação dos recursos naturais são habitadas por populações indígenas, de seringueiros e castanheiros que dependem e mantém esses recursos e, por isso, não devem ser excluídos fisicamente do parque e dos processos decisórios inerentes a sua gestão (BROWN, 1998).

Nesse sentido, a participação social na gestão de áreas protegidas se apresenta enquanto elemento fundamental para a sustentabilidade, na conservação da biodiversidade e do patrimônio natural. Essa perspectiva caminha ao encontro da chamada visão democrático-participativa que enfatiza o potencial democrático e emancipatório da participação de diferentes atores sociais nas instâncias decisórias (IRVING et al, 2006).

No caso dos remanescentes de quilombos da comunidade Tapagem, observa-se adiante a relevância do fomento à participação dos comunitários na construção de estratégias de conservação, utilização sustentável dos recursos naturais e projetos de turismo sustentável, tendo em vista sua territorialidade construída com base em etnoconhecimentos ancestrais.

A Amazônia tem servido como objeto de tentativas governamentais - e mais recentemente não governamentais - de mapeamento. Como uma última fronteira (também) cartográfica, por conter grandes áreas formalmente "desconhecidas" ou pouco estudadas, diferentes iniciativas tem procurado registrar informações geográficas, segundo diversas e muitas vezes conflitantes perspectivas como em áreas de fronteira, de reserva de recursos naturais, áreas de concentração da biodiversidade e de grupos com identidades culturais, étnicas, raciais ou sociais e seus territórios (ACSELRAD, 2008).

Almeida (2008) apresenta de forma mais incisiva a questão do modo de ocupação e utilização dos recursos como eixos norteadores que apontam para a caracterização desses grupos diferenciados. O controle dos recursos básicos 
é feito geralmente de forma coletiva, mediante normas específicas que combinam o uso comum dos recursos se voltando, entre outras formas, para atividades únicas ou combinadas como a agricultura, o extrativismo, a pesca e o pastoreio realizados de maneira autônoma ou com base no trabalho familiar.

Observando sobre o prisma da conservação e reprodução da biodiversidade engendrada através dos conhecimentos tradicionais, pode-se valer de saberes etnobiológicos e territoriais de forma a compatibilizar conhecimentos técnicos, acadêmicos e locais em busca de um planejamento turístico de matriz ecologica, cultural e economicamente sustentáveis. É neste contexto de relevância dos conhecimentos espacializados que se discute a prática de mapeamento participativo e do mapeamento êmico.

Por mapeamento participativo entende-se um processo de espacialização e registro de conhecimentos provenientes de um determinado grupo acerca de seu ambiente vivido em seus diferentes aspectos construído a partir do trabalho coletivo dos atores envolvidos e com o auxílio de instrumentos tecnológicos como imagens de satélites, cartas e mapas. Utilizando este instrumento pode-se aproximar de práticas conservacionistas mais eficientes, tendo em vista a inclusão dos conhecimentos que os atores locais possuem sobre seu ambiente vivido, trabalhando com informações que refletem efetivamente a complexidade dos ecossistemas, incluindo as prioridades locais nos objetivos dos projetos de gestão da biodiversidade (NELSON; WRIGHT, 1996).

Deste modo, considera-se o mapa participativo como ferramenta metodológica eficaz para o aprimoramento dos instrumentos de gestão e do banco de dados e informações dos determinados locais, tendo em vista seu potencial em termos de apreensão das percepções das populações tradicionais materializadas por meio de mapas e construídas de forma coletiva.

\section{Quilombo da Tapagem: Remanescentes e Mapeamento Participativo}


Dentre as diversas categorias de populações tradicionais no contexto do município de Oriximiná, observam-se as populações reconhecidas enquanto remanescentes de quilombos. Nessa região, encontra-se 33 comunidades descendentes de quilombos distribuídas ao longo dos rios Trombetas, Erepecuru, Cuminã e Acapu, constituída pelos descendentes de escravos que, nos séculos XVIII e XIX, fugiram de cacoais, fazendas e propriedades dos senhores de Óbidos, Santarém, Alenquer e Belém. Essas comunidades vivenciam o estabelecimento dos conflitos como as invasões as suas terras a partir da década de 1970, intensificadas e representadas principalmente no âmbito de: empreendimentos empresariais e estatais com a instalação da MRN, que ocupou parte do território; criação da REBIO do Rio Trombetas e da FLONA Saracá-Taquera, que impediu o acesso aos principais castanhais e implantou uma série de restrições; a edificação pela Eletronorte de uma vila para a implantação da Hidroelétrica de Cachoeira Porteira, assim como a evolução da pecuária extensiva (ARQMO, 2005).

Uma das primeiras comunidades de remanescentes de quilombos a se estabelecer abaixo de Cachoeira Porteira, na micro-região do Alto Rio Trombetas foi a comunidade reconhecida como Tapagem. A comunidade é formada por negros provenientes, em sua maioria da descendência de negros foragidos entre o final do século XVII e o século XIX no alto rio Trombetas, além de caboclos ribeirinhos da região do Vale do rio Trombetas.

Na margem direita do rio Trombetas encontra-se o lago da Tapaginha e o lago grande da Tapagem, onde se observa uma ilha que comporta o barracão e a cozinha comunitária, a igreja, o campo de futebol, a base de comunicação inter-comunitária via radiofreqüência e o único telefone público via satélite. A sua população é de 316 pessoas, subdivididas em 55 famílias, sendo 14 na ilha central e 41 dispersas. A situação fundiária dessa comunidade é bastante complexa, pois possui seu território de uso e ocupação parte pertencente à 
REBIO do Rio Trombetas $^{3}$ e a FLONA Saracá-Taquera ${ }^{4}$ e parte com reconhecimento de domínio do Governo do Estado do Pará 5 .

A partir da década de 1980, com as demandas advindas das pressões sobre seus territórios tradicionalmente ocupados, foi criada a Associação de Remanescentes de Quilombos do Município de Oriximiná (ARQMO) e mais adiante sua subdivisão para a micro-região do alto rio trombetas: a Associação das Comunidades Remanescentes de Quilombos Mãe Domingas, que comporta as comunidades Abuí, Paraná do Abuí, Sagrado Coração, Mãe Cué e Tapagem.

Com a criação da ARQMO, a luta pelos direitos dos quilombolas se institucionalizou. De acordo com seus representantes, no município de Oriximiná, das 33 comunidades remanescentes de quilombos localizadas ao longo dos rios Trombetas, Erepecuru, Cuminá e Acapu, 11 estão situadas nas duas unidades de conservação ambiental federal que ocupam parte do território do município citadas anteriormente (BRASIL, 2004).

A comunidade Tapagem, enquanto remanescente de quilombo, possui forte relação com o meio ambiente com influência indígena em vários aspectos, notadamente no uso de utensílios domésticos produzidos a partir de fibras vegetais, óleos e essências, bem como em sua alimentação, no consumo de quelônios (carne e ovos), pescados, caça, mandioca, batata-doce e extração de castanha.

A sua agricultura é baseada em pequenas roças individuais onde são cultivados mandioca, milho, arroz, pimenta, abóbora, cana-de-açúcar, feijão e frutas variadas. Os moradores produzem farinha de mandioca, coletam castanha-do-pará, breu, cipó e copaíba. A pesca é uma das atividades mais importantes para a comunidade sendo as espécies pescadas mais comuns o tucunaré e o pacu (ARQMO, informação verbal ${ }^{6}$ ).

${ }^{3}$ Decreto Federal 84.018, de 21/09/1979.

${ }^{4}$ Decreto Federal 98.704, de 27/12/1989.

${ }^{5}$ Governo do Pará. Decreto no 5.273, de 3 de maio de 2002.

6 Informações obtidas em conversa informal na sede da Associação de Remanescentes de Quilombos do Município de Oriximiná - ARQMO, em agosto de 2007. 
Algumas comunidades de remanescentes de quilombos habitam a REBIO e coletam castanhas na área há mais de um século. Na área mais acessível, ao sul da UC, ficam vários castanhais e comunidades localizados principalmente às margens do Lago Erepecu, do Lago Arrozal e Lago Araçá. Na área do Erepecu, vários castanhais como Vila Velha, Vila Veneza, Veado, Saia Velha, Água Verde, Igarapé Candieiro, Igarapé Preto, Igarapé das Pedras, Rio Novo, Jauarí e Mungubal formam de fato extensas áreas quase que contínuas. (BRASIL, 2004).

Além da extração da castanha-do-pará, as comunidades quilombolas utilizam outros produtos oriundos das matas, empregados na construção de moradias, utensílios domésticos, caça, pesca, alimentação e saúde. Entre os principais produtos destacam-se: os cipós (timbó, paxiubinha, ambé e titica), as palmeiras (ubim e inajá), os óleos (copaíba, andiroba, cumaru e pequiá), frutas (bacaba e açaí) e as resinas, a exemplo do breu (ACEVEDO; CASTRO, 1998).

Os negros se adaptaram às condições ecológicas da região, adequaramse aos diversos recursos alimentícios e suas sazonalidades, construindo aos poucos um calendário extrativo. No sentido de possibilitar sua reprodução, se organizaram de forma coletiva no uso e na apropriação da terra, fixadas por leis socialmente construídas. Deste modo, construíam uma identidade por meio das práticas, concepções e princípios comuns (ACEVEDO; CASTRO, 1998).

Ao longo de uma semana, respeitando o tempo local e seus afazeres cotidianos, realizaram-se pequenas oficinas com diferentes grupos de comunitários para a execução do mapeamento participativo com base em imagem de satélite LANDSAT 5 TM. Nesta etapa, os participantes da oficina indicam uma pessoa para ser o "mapeador", enquanto as outras o auxiliam por meio de suas interpretações visuais e conhecimentos prévios das áreas.

Sobre a imagem georreferenciada no tamanho A3 colocou-se uma folha plástica transparente de mesmo tamanho, onde o mapeador pudesse grafar os diferentes espaços classificados. O objetivo desta etapa foi espacializar na imagem de satélite o uso dos recursos naturais. Durante esta fase é normal 
ISSN: $1982-6125$

surgirem várias dúvidas quanto ao tipo de uso do espaço em algumas localidades da imagem, que são solucionadas recorrendo às observações de campo atreladas aos pontos georreferenciados. Nesse sentido, para cada utilização ou recurso utilizado foi atribuída uma folha transparente, a saber, as atividades de caça, pesca, agricultura, extrativismo de castanha-do-Pará, de recursos potenciais e da área total utilizada (Figura 2).

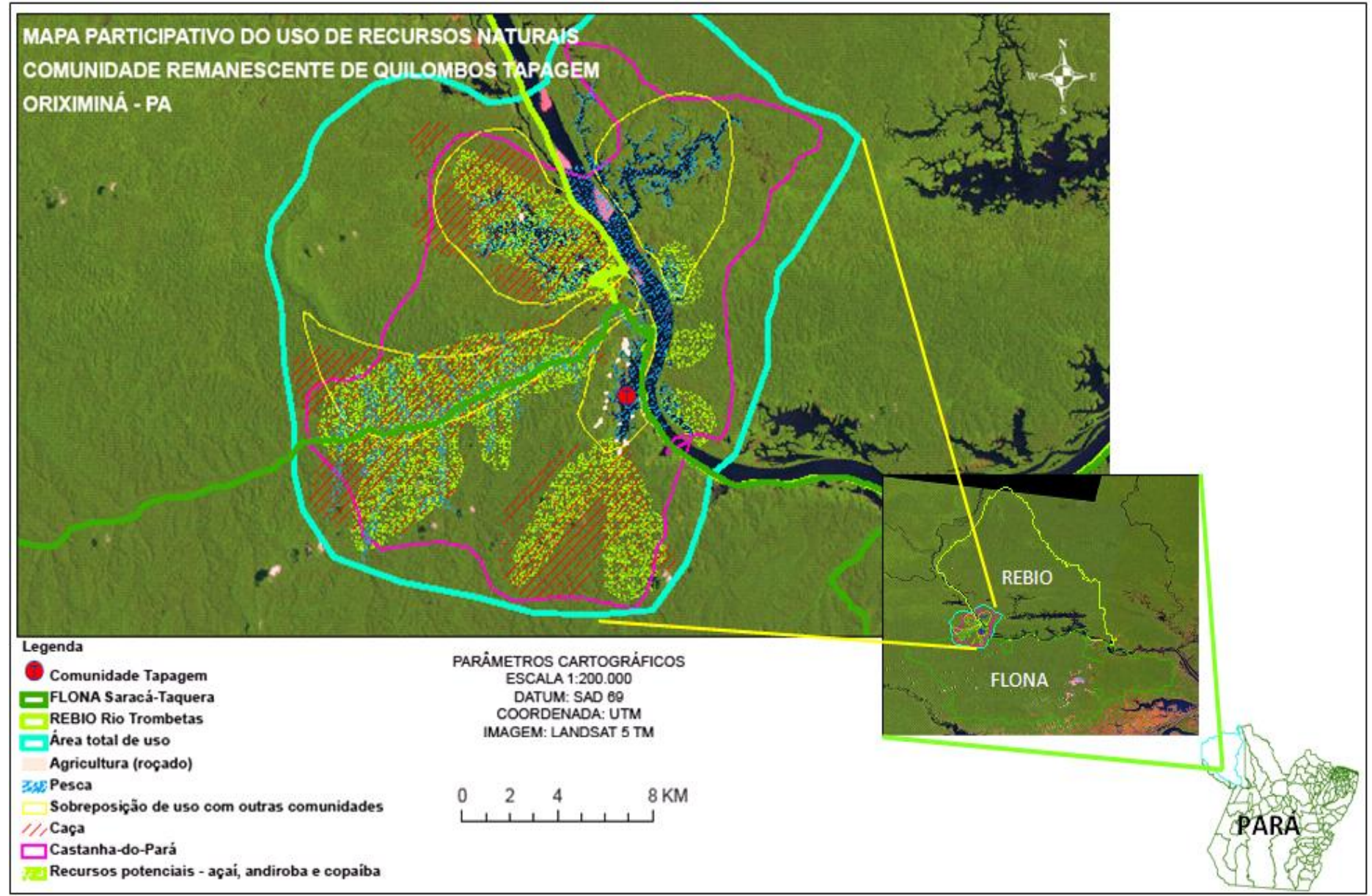

Figura 2 - Mapa participativo sintetizando o uso de recursos naturais pelos quilombolas da Tapagem

Ao final das identificações, confrontaram-se as diferentes classificações dadas pelos grupos realizando uma reunião para a definição do mapa final de cada aspecto, mapa georreferenciado elaborado integralmente pela comunidade, que contemplasse o seu raio de atuação, seja nas atividades de caça, pesca ou coleta, evidenciando seus territórios vividos e servindo de balizamento para futuros projetos de desenvolvimento, valorizando seus 
conhecimentos culturalmente adquiridos, através da espacialização de suas concepções de natureza e seus respectivos territórios.

\section{Considerações Finais}

O trabalho de análise dos diferentes usos dos recursos naturais do território estudado por meio do mapeamento participativo com os remanescentes de quilombos da comunidade Tapagem se coloca enquanto uma ferramenta útil para determinar elementos como área de uso de uma comunidade tradicional, sobreposição de usos com outras comunidades e os recursos extraídos por ela, auxiliando o processo de conservação, monitoramento, gestão e utilização adequada da biodiversidade em seus territórios e nas UC's, tendo em vista a incorporação do conhecimento local do ambiente vivido e as práticas de manejo sustentável dos recursos naturais por parte de populações autóctones.

Desta forma, o mapeamento participativo pode oferecer subsídios à formulação de políticas públicas para o desenvolvimento do turismo sustentável ao reconhecer e valorizar conhecimentos tradicionais com a promoção da autonomia econômica das comunidades quilombolas. Nesse sentido, auxilia a sistematização de conhecimentos para a efetivação de projetos turísticos sustentáveis em seu território -, o resgate e conservação da memória coletiva e o conseqüente etnodesenvolvimento.

\section{Referências}

ACEVEDO, Rosa M.; CASTRO, Edna. Negros do Trombetas; guardiães de matas e rios. 2.ed. Belém: Cejup/UFPA-NAEA, 1998.

ACSELRAD, H. (Org.). Cartografias sociais e território. Rio de Janeiro: IPPUR/UFRJ, 2008.

ALMEIDA, A. W. B. Terra de quilombo, terras indígenas, "babaçuais livre", "castanhais do povo", faxinais e fundos de pasto: terras tradicionalmente ocupadas. 2.ed. Manaus: PGSCA-UFAM, 2008. 
ARQMO - Associação dos Remanescentes de Quilombos do Município de Oriximiná. Projeto manejo dos territórios quilombolas. São Paulo: CPI, 2005. Disponível em <www.quilombo.org.br>. Acesso em 27 mar. 2007.

BECKER, B. K. Ciência, tecnologia e inovação para conhecimento e uso do patrimônio natural da Amazônia. Revista Parcerias Estratégicas, n.20, jun. 2005. (Seminários temáticos para a $3^{a}$ Conferência Nacional de C,T\&I)

BRASIL. Ministério do Meio Ambiente. MAURY, C. M. (Org.). Biodiversidade brasileira. Brasília: MMA/SBF, 2002.

Plano de manejo da Reserva Biológica do rio Trombetas, estado do Pará. Brasília, jul.2004.

BROWN, I. F. et al. Mapa como ferramenta para gerenciar recursos naturais: um guia passo-a-passo para populações tradicionais fazerem mapas usando imagens de satélite. Rio Branco: Brilhograf, 1998.

DIEGUES, A. C. (Org). Etnoconservação. Novos rumos para a conservação da natureza. São Paulo: Hucitec/NUPAUB-USP, 2000.

IRVING, M. et al. (org.). Áreas protegidas e inclusão social: construindo novos significados. Rio de Janeiro: Fundação Bio-Rio/Núcleo de Produção Editorial Aquários, 2006.

NELSON, N.; WRIGHT, S. Participation and power. In: NELSON, N.; WRIGHT, S. Power and participatory development. Theory and practice. Ed. Intermediate Tachnolgy Publications, 1995.

PIMBERT, M. P.; PRETTY, J. N. Parques, comunidades e profissionais: incluindo "participação" no manejo de áreas protegidas. In: DIEGUES, A. C. (Org). Etnoconservação. Novos rumos para a conservação da natureza. São Paulo: Hucitec/NUPAUB-USP, 2000.

THEODORO, S. H. (Org.). Mediação de conflitos socioambientais. Rio de Janeiro: Garamond, 2005.

Artigo recebido em outubro de 2011.

Aprovado para publicação em dezembro de 2011. 